Roloff) and flower pieces and genre pictures (Berndt).

The sample reproduction submitted for review is "Horses in a Storm" by A. Roloff ( 24 in. by $29 \frac{3}{4}$ in., $52 s .6 d$.). 'This print admirably conveys the feeling and tonal qualities of the original, for the impasto, though evident, is not intrusive. From the purely technical point of view, closer register in the printing would have added to the excellence of this reproduction; but this does not detract from the fact that it is a splendid piece of printing. Moreover, the reproduction itself conveys the gripping vitality of the original; yet withal it is unusual among horse paintings in that the artist strikes the reviewer as having, with consummate cunning, transferred action and virility from the animals to the elements around them. So excellent is this reproduction of a superb painting that anyone would surely be proud to possess it.

Men of science, whether academically interested in art or practically concerned with décor, would do well to examine this catalogue (a piece of good printer's art in itself). Geographers and natural historians might show more specific interest and appreciation; but all will be grateful to the Pallas Gallery, Ltd., for making these prints again available, and at such comparatively modest prices.

L. J. F. Brimble

\section{AMERICAN PHILOSOPHICAL SOCIETYY YEAR BOOK FOR 1953}

T HE "Year Book 1953" of the American Philosophical Society* covers the year ended December 31, 1953, and includes the customary brief history of the Society, and a copy of its charter and laws, together with lists of officers and committees and members, biographical memoirs and the reports of standing committees. The report of the Committee on the Library refers to satisfactory progress in implementing the Darwin programme and says that the search for secondary material. pertaining to the evolution theory is meeting with much success; nearly five hundred volumes have been added, and more letters to and from Darwin and his associates have been acquired. The collection promises to become one of the foremost on the subject in the world.

More than a third of the volume is occupied by the report of the Committee on Research, which details 151 grants, totalling 135,661 dollars, from the Penrose Fund, eight, totalling 15,750 dollars, from the Johnson Fund, and eight, totalling 15,255 dollars, from the Daland Fund for Research in Clinical Medicine. Five grants, totalling 15,700 dollars, were also made during the year from the Michaux Fund. This part of the report consists mainly of brief reports from recipients of grants, arranged alphabetically by sciences. Among the more detailed of these summaries may be mentioned those of the following: O. Struve, on measurements of the spectrum of Capella, which point to 0.9 for the mass ratio of the cool component to the hot component; H. L. van Dyke, on the formation of alkylbenzenes through the Friedel-Crafts, Fittig and Grignard

* American Philosophical Society. Year Book 1953, January 1, 1953-December 31, 1953. Pp. 517. (Philadelphia : American Philo-
sophical Society, 1954.) reactions; H. S. Colton, on Lower Pliocene mammalian fauna from near Walnut Grove, Yavapai County, Arizona; R. Chambers, on studies of the permeability of the egg of Fundulus (sea minnow) to water and electrolytes, which suggest that the constant plateau level of the pressure observed when the eggs, activated by puncture, were freshly shed into sea water, is due largely, if not entirely, to the ability of the perivitelline colloid to hold water, and possibly electrolytes, irrespective of the tonicity of the surrounding media; S. S. Roback, on the tendipedid larvæ of the Philadelphia area; R. I. Sailer, on the significance of hybridization among stink bugs of the genus Euschistus; and T. A. Stephenson on plant and animal ecology of the seashore between tide-marks in the Bermuda islands in which a flourishing colony of the unusual barnacle Catophragmus imbricatus was discovered, and evidence obtained that the progressive smoothing-off of the æolian limestone around Bermuda between the high-water and low-water level is due to a considerable extent to the browsing activities of beaked fishes and of various invertebrates. F. W. Crane, studying the diagnostic characters of fern spores, particularly of Dryopteris, reports that the species of Dryopteris observed can be separated on the basis of spore characters, that the hybrids are easily recognized as such by their peculiar spore production and that hybrid spores are not in themselves completely diagnostic ; the morphology of the specimen must be considered. J. Merkle reports on an ecological analysis of the meadows on the Kaibab Plateau, Arizona; F. D. Reed on progress with a monograph on the Calamites; D. J. Rogers on variations in Manihot utilissima and related species in Jamaica and Costa Rica; and W. A. Weber on variation in Balsamorhiza (Compositae).

R. A. Waterman describes an ethnological and ethnomusicological field investigation of the aboriginals of Yirkala, North-Eastern Arnhem Land, Australia; N. C. Li reports on his investigations on the stability of zinc complexes with glutathione and oxidized glutathione and of copper II complexes with oxidized glutathione; D. W. Wilson on investigations of the biochemistry of nucleic acids with the Beckman ultra-violet spectrophotometer and the International refrigerated centrifuge; and L. W. Bluemle on the application of extra-corporeal hæmodialysis to remove œdema fluid, re-evaluate the toxic factors in uræmia and in studying the effect of dialysis upon the production of urea, in which the value and versatility of the artificial kidney in treating and investigating problems of fluid and electrolyte metabolism have been demonstrated.

Among reports on research work grouped under the humanities which are of scientific interest may be noted those of E. G. Allen on John Abbot, the ornithologist of Georgia, which should facilitate the writing of his biography as well as an account of his pioneer work in natural history in America; G. E. Fay on the archrological cultures of the southern half of Sonora, Mexico; A. J. B. Wace on excavations at Mycenæ, Greece; S. S. Weinberg on the comparative archæology of the Egean and the Near East in the Neolithic period; W. D. Wallis on the ethnography of the Maliseet (Malicete) and of the Micmac Indians of New Brunswick, Canada; and G. M. A. Hanfmann on the development of geometric and orientalizing art in Ionia with special reference to vase-painting and minor arts. 